\title{
ANALYSIS OF THE PREVALENCE OF JOINT DEFORMITIES CORRELATING WITH BRAZILIAN REGION
}

Thalia Souza Bezerra (Unifor, Fortaleza, CE, Brasil), Manoella Gotardo Aguiar Gurgel (Unifor, Fortaleza, CE, Brasil), Isa Cavalcanti Martildes (Unifor, Fortaleza, CE, Brasil), Guilherme Bitu dos Santos Ponte (Unifor, Fortaleza, CE, Brasil), Larissa Holanda Gomes (Unifor, Fortaleza, CE, Brasil), Priscila Dourado Evangelista (Unifor, Fortaleza, CE, Brasil)

\section{BACKGROUND}

Due to population-ageing, joint deformities have become increasingly recurrent in our society. In advanced ages there is a remodeling of the cartilages, causing a reduction in its thickness and alteration of its color, as well as the decrease of the synovial fluid present in the articular capsules, which diminishes its capacity of compressive resistance, leading to a greater erosion of the joint surface. These alterations impair the joint's functionality and increase the development of joint deformities predispositions. Besides aging, there are other factors that corroborate with joint vulnerability and its degeneration, such as gender, heredity, sedentary lifestyle, stress and associated chronic diseases. Rheumatic diseases induce a physical limitation to the affected patients, causing a difficulty to accomplish their daily activities, which severely impairs their life quality and mental health. Among rheumatic diseases, rheumatoid arthritis and osteoarthrosis stand out, which represent the most prevalent rheumatic disorders. The present study aims to analyze the prevalence of joint deformities in Brazil and its correlation with the different Brazilian regions.

\section{MATERIALS AND METHODS}

Descriptive cross-sectional study, based on DATASUS information, considering the period from 2008 to 2018.

\section{RESULTS}

The sample consisted on 76,582 people with hospitalizations between 2008 and 2018, of any age group, both gender and residents of Brazil. Regarding to the years of highest and lowest prevalence, there were 7,865 admissions in 2018 and 6,318 in 2012. The southeastern region was highlighted by the high number of hospitalizations, consisting of 39,682. The southern region was the second in number of occurrences, with 20,107 hospitalizations. The region with the highest prevalence of joint deformities was in the South, with 70.49 cases per 100,000 inhabitants, followed by the Southeast (47.43 / 100,000 inhabitants), then Central West (36.77 / 100,000 inhabitants), Northeast (16, 97 / 100,000 inhabitants) and, finally, North (11.73 / 100,000 inhabitants). The prevalence of Brazil in this period was 38.49 cases per 100.000 inhabitants.

\section{CONCLUSION}

We conclude that the acquired joint deformities have an unequal prevalence in the Brazilian territory, concentrated in the most developed regions of the country. Further studies are needed to ascertain if such inequalities are due to epidemiological factors, such as a higher prevalence of diseases capable of causing deformities, or if there is a bias related to the underreporting of cases in the less developed regions of the country. 